\title{
Intense Daily Physical Work to Curtail Obesity and Metabolic Complexities: A Global Initiative
}

\author{
Akbar Nikkhah* \\ Department of Animal Sciences, University of Zanjan, Iran
}

Submission: September 28, 2015; Published: October 10, 2015

*Corresponding author: Akbar Nikkhah, Chief Highly Distinguished Professor, Department of Animal Sciences, Faculty of Agricultural Sciences, University of Zanjan, Foremost Principal Highly Distinguished Elite-Generating Scientist, National Elite Foundation, Iran; E-mail: anikkha@yahoo. com

\begin{abstract}
Obesity and related metabolic challenges are amongst major health concerns of the modern age. Demanding public edification on standardizing, localizing, and globalizing consistent, intense, and durable physical activity on a daily basis is a must for minimizing excess weight gain and obesity. It is pragmatically inefficient to concentrate on weight loss management or metabolic diseases treatment. Efforts must be made to formulate efficacious prevention strategies to successfully reduce obesity and its related health issues. This article discusses stable intense exercise of intense and daily nature as a feasible approach against obesity outbreak in today's complicated lifestyles.
\end{abstract}

Key words: Obesity; Education; Stable Physical Work

\section{Discussion of Philosophy}

Obesity is unarguably a challenge to quality human life in modern and postmodern times. It would not be surprising to name obesity a super cancer of the overly modernized man. This is mainly because obesity makes the body prone to numerous other diseases and health abnormalities. The existing public health and education plans are to be greatly criticized in terms of accuracy and expected results. Education must begin to renovate towards pragmatic body weight management and improved lifestyles. On top of priorities is certainly reshaping public education to incorporate rhythmic daily physical work with stable structures to increase success of obesity-minimizing strategies $[1,2]$.

Fundamentally, life on earth is characterized by its circadian rhythms based on which human physiology and metabolism are synchronized and harmonized with the surrounding environment $[3,4]$. It is urgent to contemplate the main reasons behind failure of weekly requirement formulation for physical activity. Such settings cannot specify and accurately predict and meet critical levels of cell and tissue requirements for substrate assimilation and oxidation rates towards healthy and efficient waste management [1,5-7]. This is because cells are continuously exposed to substrate supply and use throughout the lifespan. Thus, cells accordingly require management tools to function healthfully through obtaining energy and managing waste in a timely manner. Frequent daily and rhythmic exercise describes an optimal pragmatic physiological manager that cells are in great need of.

Establishing regular and well-adjusted circadian patterns in cellular substrate delivery and utilization is a prerequisite for functional and health-improving cell physiology [8,9]. For optimal metabolic turnover and health, nutrients and their resulting substrates must be supplied to differential cells uninterruptedly without long delays or intervals. This property describes the almost 24-hour or circadian rhythmicity of cell metabolism. Such regular diurnal and nocturnal rhythms must be matched with their parallel rhythms of substrate utilization/ oxidation/expenditure and waste management for cells to function healthfully and economically. Consequently, energy expenditure must increase in response to any increase in energy intake equally and shortly thereafter to optimize metabolism and health. Increased substrate utilization is best achieved through rhythmic and daily physical and brain activities [5,10-12].

A foremost innovative aspect of the present pragmatic public article is its foundation of a global awareness for a determination to educate and exercise daily and regular physical work of sufficient intensity. In other words, short or undemanding physical activity (e.g., sluggish walking) has only minor benefits towards improving human health. Any adequate physical work must increase heart beating significantly for at least 25-30 min daily, sweating, stomach desolation, and a post-exercise crave for energy and water intake. These must occur persistently on a daily basis for an exercise session to be considered health-improving. The crave for food must not be met by energy over-consumption, 
otherwise it would harm both the body and mind. Therefore, it is indeed delicate how to keep balance between substrate supply and demand through careful and timely eating and exercise. This requires further extensive research. In a nutshell, metabolic complexities of namely diabetes and related cardiovascular issues and even cancer may be prevented through matching circadian rhythms of eating, exercising and resting [13,6,7,14-16].

\section{Conclusion}

Global initiatives must be taken to formulate and execute innovative public health and education plans for daily intense exercise. Such a rhythmic and regular physical work ensures that differential cells and tissues receive timely and circadian inductions to augment optimal nutrient/substrate oxidation, whereby matching the continuous patterns of substrate intake via eating. Enervation and durable sweating are key signs of adequately intense exercise for a minimum of 20-30 min daily, should optimal weight management and minimized obesity risk be sought.

\section{Acknowledgments}

Thanks to the Ministry of Science Research and Technology and National Elite Foundation for supporting the author's global initiatives and programs of optimizing science edification in the third millennium.

\section{References}

1. Nikkhah A (2015) Evening Exercise: A Global Strategy to Prevent Central Adiposity and Crdiometabolic Diseases. Adv Weigh Manag Obes Cont, In Press.

2. Nikkhah A (2015) Breast health progress through exercise-driven lactation: A pragmatic bioprocess to prevent cancer. J Bioprocess Biotechniq, In Press.

3. Sehgal A (2004) Molecular Biology of Circadian Rhythms. John Wiley \& Sons, Inc., Hoboken, NJ, USA.
4. Nikkhah A (2012) Science of eating time: A novel chronophysiological approach to optimize glucose-insulin dynamics and health. Journal of Diabetes Mellitus 2(1): 8-11.

5. Nikkhah A (2015) Nature as an Ideal Rhythm Model for Optimal Cardiovascular physiology and Health. Int J Diabetol Vasc Dis Res 3(2e): 1-2.

6. Nikkhah A (2015) Harmonizing Eating and Exercise Circadian Rhythms for Optimal Glucose-Insulin and Vascular Physiology. Int J Diabetol Vasc Dis Res 3(3): 87-88.

7. Nikkhah A (2015) A Time-Efficient Exercise Formula for Normalizing Obese Body Mass Index. Adv Obesity Weight Manag Cont 3(2): 00049.

8. Nikkhah A (2015) Wrecked oncogenesis through synchronized substrate availability and oxidation: A novel bioengineering of cell physiology. Aust J Biotechnol Bioeng 2(2): 1042-1043.

9. Nikkhah A (2015) Timely Outdoor Physical Work Postpartum for Healthy Maternal Recovery. J Preg Child Health 2:3.

10. Nikkhah A (2015) Secure Weight Management via Fitting Circadian Patterns of Physical Activity, Resting and Eating. Adv Obes Weigh Manag Control 2(4): 00023.

11. Nikkhah A (2015) Effective Weight Management in Periparturient Women through Optimizing Eating Timing: A Novel Global Approach. Adv Obes Weight Manag Control 2(3): 00018.

12. Nikkhah A (2015) Circadian Fitting of Exercise and Eating Patterns: The Secret of Healthy Life. J Bioprocess Biotech 5: e129 doi: 10.4172/ e1295-9821.1000e129.

13. Nikkhah A (2015) Living on Healthy Rhythms to Overcome Cancer: A Public Therapeutic. J Nutr Therap, p: 39-40.

14. Nikkhah A (2015) Lifestyle Optimization: Today's Foremost Probiotic. J Probiotics Health. 3: e119. doi:10.4172/2329-8901.1000e119.

15. Nikkhah A (2015) Vital Frontiers of Science Education: Global Obligations. Adv Crop Sci Tech 3: e126. doi:10.4172/2329$8863.1000 \mathrm{e} 126$.

16. Nikkhah A (2015) Improving Life Quality via Circadian Timing of Nutrient Intake: Linking Ruminant Agriculture to Human Health. EC Agriculture 2(1): 258-259. 